\title{
Genel Politik Etkinlik Ölçeği: Sağlık Çalışanlarında Bir Ölçek Geliştirme Çalışması
}

\author{
Hilal KUŞCU KARATEPE*, Derya ATİK**
}

ÖZ

Araştırma, sağlık çalışanlarının politik etkinlik düzeylerinin belirlenmesinde bir ölçüm aracı geliştirmek amacıyla metodolojik olarak gerçekleştirilmiştir. Çalışmaya 200 sağlık çalışanı katılmıştır. Ölçek maddelerinin yüzey ve kapsam geçerliliği sağlanmıştır. Verilerin değerlendirilmesinde SPSS 21 ve AMOS 22 programları ile sayı yüzdelik hesaplama, korelasyon, açıklayıcı ve doğrulayıcı faktör analizi yapılmıştır. Açıklayıcı faktör analizinde 26 maddelik İçsel, Dışsal olmak üzere 2 alt boyutlu yapının ortaya çıktığı belirlenmiştir. Doğrulayıcı faktör analizinde uyum iyiliği değerleri ölçütlerini sağladığı ortaya çıkmıştır. Ölçek geneli Cronbach Alpha değeri 0,96'dir. Alt boyutlar için; içsel alt boyutu Cronbach Alpha değeri 0,93 ve içsel alt boyutu Cronbach Alpha değeri 0,94'tür. Sonuç olarak, Politik Etkinlik Ölçeği geçerli ve güvenilirdir.

Anahtar Kelimeler: Politika, Etkinlik, İçsel, Dışsal, Sağlık Çalışanları

JEL Sinıflandirması: D72, O17

\section{General Political Activity Scale: A Scale Development Study in Healthcare Employees}

\begin{abstract}
The research was carried out methodologically to develop a measurement tool for determining the level of political efficiency of health employees. 200 healthcare employees participated in the study. Surface and scope validity of scale items were provided. In the evaluation of the data, SPSS 21 and AMOS 22 programs were used to calculate the number percentage, correlation, explanatory and confirmatory factor analysis. In the explanatory factor analysis, it was determined that there were 2 sub-dimensional structures with 26 items as Internal and External. It was revealed in the confirmatory factor analysis that it met the criteria for goodness of fit values. The scale-wide Cronbach Alpha value is 0.96. For the sub-dimensions; The internal sub-dimension Cronbach Alpha value is 0.93 and the internal sub-dimension Cronbach Alpha value is 0.94. As a result, the Political Effectiveness Scale is valid and reliable.
\end{abstract}

Keywords: Policy, Activity, Internal, External, Health Employees

JEL Classification: D72, O17

\footnotetext{
* Dr. Öğr. Üyesi, Osmaniye Korkut Ata Üniversitesi, Sağlık Bilimleri Fakültesi, Hemşirelik Bölümü, hkuscukaratepe@osmaniye.edu.tr, ORCID: 0000-0001-9237-2714.

** Doç. Dr., Osmaniye Korkut Ata Üniversitesi, Sağlık Bilimleri Fakültesi, Hemşirelik Bölümü, deryaözcanli81@ hotmail.com, ORCID: 0000-0002-8497-0105.
} 


\section{GİRİŞ}

Sağlık bir sosyal olgudur. Politika ise her sosyal olgunun olduğu gibi sağlik hizmetlerinin de temel belirleyicisidir. Sağlı alanında verilen hizmeti, hizmet alanları ve hizmet verenleri direkt etkilemesi; sağllk personelinin yeterlilik durumu, sorumluluk, hak ve yetkileri kapsayan yasalar ile mesleki uygulamalara vermesi ve mesleki profesyonelleşmedeki rolüyle oldukça önemlidir (Chitty, 2001; Harmancı Seren, 2014; Yıldırım, 2014). Ayrıca toplum içindeki işleyişlerde, önemli ortak kararların alınmasında; bireysel, toplumsal, meslek yaşam kalitesinin artırılmasında da rol oynar. Bu bağlamda politika ve ilgili kavramların bilinmesi ve geliştirilmesi gerekir. Politika ile ilgili önemli kavramların birisi de politik etkinliktir.

Politik etkinlik "bireysel politik eylemin politik süreç üzerinde bir etkisi olduğu ya da olabileceği hissi, yani kişinin sivil görevlerini yerine getirmede bir değer" olarak tanımlanır (Campbell vd., 1954). Farklı1ıkları olmasına rağmen, öz yeterlik teorisine dayandırılır (Bandura, 1982; Gist ve Mitchell, 1992) ve insanlar yapmak istedikleri şeyi başaracaklarına inanarak yaparlar (Pingree, 2011; Kuşcu Karatepe, 2019). Vatandaşların politik sistemi etkileme becerisine sahip oldukları konusundaki inançlarını kapsar (Zimmerman, 1989). Yurttaşların siyasi faaliyetleri yoluyla ülkesinin politik sistemini şekillendirmeye, katılım yetenekleri ve etkileri konusundaki inancıdır. Kişinin demokratik sürece etkin bir şekilde katılma becerisine duyduğu güvendir (Niemi vd., 1991; Morrell, 2003). Politik etkinlik ile birey, politik ve toplumsal değişimin mümkün olduğunu hisseder ve bireysel olarak vatandaş olarak da bu sistemi değiştirmede rol oynayabileceğini düşünür (Kenski ve Stroud, 2006). Bireyin politikadaki etkinliğini, kişinin demokratik bir sistemdeki sorunları çözme yeteneğine güven duygusu geliştirip geliştiremeyeceğini belirler (Mill, 1991). Politik etkinlik, yaşamdaki deneyimlerin katılımcı davranışları nasıl şekillendirdiğini inceler (Bandura, 1991). Politik etkinliğin günlük yaşamda politikanın önemini arttırdığı ve demokratik normlarla yakından uyumlu davranışlara yol açtığı düşünülür. Artan bir politik etkinlik duygusu, politik bilgi düzeylerini, oylama olasılığını, kamu görevlileriyle iletişim kurmayı, mitinglere katılmayı ve politik müzakere etmeyi sağlar (McLeod ve McDonald, 1985; Bennett, 1997; Gastil ve Dillard, 1999; Bilge, 2003).

Birçok bilim insanına göre politik etkinlik iki türdür: Kişisel etkinlik duygusu (içsel etkinlik) ve sistem odaklı etkinlik duygusudur (dışsal politik etkinlik) (Mohammed, 2011; Kuşcu Karatepe, 2019). İçsel etkinlik; "öz-yeterlik", "sonuç beklentileri”, "bir kişinin belirli bir davranışın belirli sonuçlara yol açacağı tahmini", "etkinlik beklentileri" ve "sonuçların üretilmesi için gerekli davranışı başarılı bir şekilde yürütebileceğine dair inanç" yanında bireyin amaçlanan hedefi elde etmek için başarılı bir şekilde hareket edebilme beklentisidir (Bandura, 1977). Politika ile ilgili olarak, bu, kişinin politik gerçekleri ve süreçleri anlayabileceği, politikayı başarılı bir şekilde etkileyebileceğini hissettiği hissini içerir (Campbell vd., 1954; Almond ve Verba, 1965; Balch, 1974). Sonuç olarak, içsel politik etkinlik, kişinin davranışsal becerilerine olan inanc1 ve üstlenilen eylemlerin bir etkisi olacağı gibi, kişinin politik bilgisinin öznel değerlendirmesini içerir.

İçsel politik etkinlik "bireysel politik güven" (Krampen, 2000) "bireysel politik özyeterlik" (Veneziano ve Hooper, 1997) anlamı ile bireysel güç temsilidir. İ̧sel politik etkinlik hem rasyonellik hem de motivasyon unsurlarını bir araya getirdiği için siyasi katılım ve rasyonel yollarda motivasyon faktörü olarak kabul edilmesi şaşırtıcı değildir (Jung vd., 2011; Condon ve Holleque, 2013). Birçok çalışma içsel politik etkinliğin politik katılımda önemli ve olumlu bir rol oynadığını vurgulamıştır (Krampen, 2000; Schulz vd., 2010; Condon ve Holleque, 2013). Günlük yaşamda politik faaliyet sıklı̆̆ı, politik yetkinlik, politik bilgi, oy kullanma davranışları etkiledikleri alanların bazılarıdır. Bu nedenle, politik bilgi gibi içsel politik etkinlik de politik katılımın öncüleridir (Westle, 2011; Gallego ve Oberski, 2012; Johann, 2012)

Dışsal politik etkinlik ise, vatandaşların hükümetin vatandaşların taleplerine yanıt verme 
konusundaki algılarını ifade eder (Converse, 1972; Balch, 1974). Kişinin sisteme olan inancıdır (Cornfield, 2003). Devlet makamlarının, kurumların vatandaşların taleplerine cevap vereceği düşüncesi ve vatandaşların buna olan inancıdır (Kenski ve Stroud, 2006). Demokratik sistemin bir gereğidir (Cornfield, 2003). Dışsal etkinlik, teoride, seçmen, politikacı, vatandaş tarafından seçilmiş resmi (Craig vd., 1990) politika ile ilgili etkinlik önlemlerinin çeşitliliğini garanti eder (Velasquez ve LaRose, 2015).

Politik etkinlik çok boyutlu bir yapıdır (Craig vd., 1990; Niemi vd., 1991). Diğer algısal ve psikolojik değişkenlere benzer şekilde, politik etkinlik kavramı oldukça bağlamsaldır (Gil de Zúñiga, 2006). Sosyo-ekonomik faktörler politik etkinliği, özellikle içsel etkinliği büyük ölçüde etkiler. Çalışmalar eğitim, medya, başkalarıyla politika hakkında konuşma gibi unsurların içsel etkinlikle diğer değişkenlere nazaran daha güçlü bir ilişkisi olduğunu göstermiştir (Kenski ve Stroud, 2006). Bunun yanında bazı araştırmacılar da etkinlik düzeyi ile demografik değişkenler, politikayı izleme seviyesi, gazeteleri takip etme ve politik ilgi ve bilgi arasında pozitif korelasyon olduğunu öne sürmüşlerdir. Başka bir araştırma ise, interneti bilgi, özellikle politik bilgi için kullananların daha yüksek düzeyde politik etkinlik sergilediklerini ortaya koymuştur. Yine aynı araştırmada internet kullanım düzeyleri yüksek olanların politik kampanyalara ve politikaya katılma olasılıklarının arttığını göstermiştir (Johnson ve Kaye, 2003; Kenski ve Stroud, 2006, Wang, 2007).

$\mathrm{Bu}$ çalışmada sağlık çalışanlarında Politik Etkinlik Ölçeği’nin geliştirilmesi, geçerlilik ve güvenirliğinin belirlenmiştir. Bu doğrultu ilk kez geliştirilen Politik Etkinlik Ölçeği ile politikadan birçok alanda etkilenen sağlık çalışanlarının politik sistemi etkileme güçlerine yönelik inançlarının değerlendirerek ulusal ve uluslararası pek çok alana katkı sağlayacağı öngörülmektedir.

\section{YÖNTEM}

Bu çalışmada sağlık çalışanlarının politik etkinlik düzeylerini belirlemek amacıyla bir ölçüm aracı geliştirmek amaçlanmıştır. Araştırma metodolojik tiptedir. Hatay ilinde bulunan bir özel hastanede Nisan-Aralık 2019 tarihlerinde yapılmıştır. Araştırmanın evreni Hatay ilinde bir özel sağlık kuruluşunda çalışan tüm sağlık çalışanlarıdır. Araştırma evreni ve örnekleminin ölçek çalışmalarında her bir ölçek maddesinin minimum beş katı veya daha fazlasının örnekleme alınması önerilmektedir (Yurdugül, 2005). Bu nedenle çalışmada örneklem sayısı olarak madde sayısının minimum beş katı büyüklüğünde örnekleme ulaşılması planlanmıştır. Araştırmanın örneklemi rassal örneklem yöntemi ile Nisan-Aralık 2019 tarihlerinde Hatay ilinde bir özel hastanede çalışmakta olan ve çalışmaya katılmaya gönüllü olan 200 sağlık çalışanı oluşturmuştur. Hatay ilinde seçilmesinin nedeni bölgedeki özel sağlık kuruluşları içerisinde istenilen sayıda sağlık çalışanına sahip olmasıdır. Bu çalışmada araştırma tarihleri içerisinde 200 sağlık çalışanına ulaşılmış ve elde edilen anketlerin tamamı araştırmaya dahil edilmiştir. $\mathrm{Bu}$ çalışmada aşağıda belirtilen iki soruya cevap aranmıştır. Bunlar;

\section{Genel Politik Etkinlik Ölçeği geçerli midir?}

Genel Politik Etkinlik Ölçeği güvenilir midir?

Veri Toplama Araçları olarak; ilk form araştırmacı tarafından oluşturulan sağlık çalışanlarının sosyo-demografik özelliklerini belirlemeye yönelik Kişisel Bilgi Formudur ve katılımciların cinsiyet, medeni durum, eğitim, hafta sonu çalışma durumu, idari görevde bulunma durumu, görev, dernek üyeliği, aylık gelir, çalışma yılı ve haftalık çalışma saati gibi özellikleri belirlemeye yönelik 11 maddeden oluşmaktadır. İkinci form olarak ise, Genel Politik Etkinlik Ölçeği geliştirilmiştir. Ölçekte ilk aşamada toplamda 30 maddelik hali ile taslak formunda veriler toplanmıştır. Daha sonrasında yapılan ilgili analizler ile nihai olan 26 maddelik 
Politik Etkinlik Ölçeği İçsel ve Dışsal olmak üzere iki alt boyut altında ortaya çıkmıştır. Çalışmanın devamında uygulanan analiz yöntemlerine detaylıca yer verilmiştir. Verilerin elde edilmesinde ölçek puanlamasında 5'li Likert tipi ölçek puanlaması tercih edilmiştir. Ölçek puanlaması "1=Hiç Katılmıyorum, 2=Az Katılıyorum, 3=Katılıyorum, 4=Oldukça Katılıyorum, 5=Tamamen Katıliyorum" şeklindedir. 1-2 arası puanlar maddeye katılmama durumunun azalan şekilde belirtilmesi, 3-5 arası puanlar maddeye katılım durumunun artan şekilde belirtilmesi için kullanılmıştır. Maddelerin tamamı olumlu ifadedir. Ölçek puanlamasında en düşük puan 26 ve en yüksek puan 130 'dur. Ölçeğin Cronbach Alpha değeri 0,96'dır.

İzin alınan kurumda araştırmacılar tarafından çalışanlar ile yüz yüze görüşme sağlanmış araştırma ile ilgili bilgi verilmiş, doldurulacak ölçek ve form tanıtılarak yaklaşı 10-15 dakikalık bir sürede tamamlanabileceği belirtilmiştir. Araştırmada elde edilen verilerin değerlendirilmesinde SPSS 21 ve AMOS 22 paket programı ile yapılmış ve $\% 95$ güven aralığ 1 ile çalışılmıştır. İncelenen özellik ve kullanılan istatistiksel yöntemler Tablo 1'de belirtilmiştir. Bu çalışmanın etik onayı (27/03/2019 tarihli 2019/4/3 sayıl1) Osmaniye Korkut Ata Üniversitesi Bilimsel Araştırma ve Yayın Etiği Kurul Başkanlığı'ndan; araştırma kapsamına alınan uygulama izni Özel Akademi Hastanesi Başhekimliği’nden alınmıştır.

Tablo 1: Kullanılan İstatiksel Yöntemler

\begin{tabular}{l|l}
\hline \multicolumn{1}{c|}{ Íncelenen Özellik } & \multicolumn{1}{c}{ İstatistiksel Yöntemler } \\
\hline Geçerlilik Analizleri & $\begin{array}{l}\text { Kapsam Geçerliği (Lawshe tekniği ile KGO ve KGİ } \\
\text { hesaplama) } \\
\text { Yapı Geçerliği (Açıllayıcı Faktör Analizi, Doğrulayıcı Faktör } \\
\text { Analizi) }\end{array}$ \\
\hline Güvenirlik Analizleri & $\begin{array}{l}\text { Madde analizi (Pearson Korelasyon) } \\
\text { Cronbach Alpha İç Tutarlık Katsayısı } \\
\text { Spearman-Brown İç Tutarlık Katsayısı } \\
\text { Guttman İç Tutarlık Katsayısı }\end{array}$ \\
\hline $\begin{array}{l}\text { Zamana Göre Değişmezlik Analizi (Test-Tekrar } \\
\text { Test Uygulaması) }\end{array}$ & \begin{tabular}{l} 
Pearson Korelasyon Katsayısı \\
\hline
\end{tabular}
\end{tabular}

\section{BULGULAR}

\subsection{Kişisel Verilere Ait Bulgular}

Hemşirelere ait kişisel verilerin dağılımı Tablo 2'de gösterilmiştir. Tablo 2'de kişisel verilerin dağılımında; katılımcıların \%66'sı kadın \%34'ü erkektir. Medeni durum olarak; $\% 61,5$ 'inin evli \%38,5'inin ise bekar olduğu belirlenmiştir. Eğitim düzeyleri incelendiğinde; \%30,5'inin lise mezunu, \%15,5'inin önlisans, \%38'inin lisans ve \%16'sinın ise yüksek lisans/doktora mezunu olduğu belirlenmiştir. Hafta sonu çalışma durumu olarak; katılımcıların \%87'sinin hafta sonu çalıştığı belirlenirken, \%13'ünün hafta sonu çalışmadığı belirlenmiştir.

Çalışma statüsü olarak; \%62,5'inin hemşire, \%16'sının doktor, \%5,5'nin fizyoterapist, \%10'unun laboratuvar teknisyeni ve \%6'sının sağlı kurumunun diğer birim çalışanları olduğu saptanmıştır. Katılımcıların \%19'unun dernek üyeliğinin bulunduğu saptanırken \%81'inin mesleki derneğe üyeliğinin bulunmadığı görülmüştür. Katılımcıların yaş ortalamasının 
$31,36 \pm 11,38$, aylık gelir ortalamasının $4096,10 \pm 3851,62$, çalışma yılı ortalamasının $10,06 \pm 10$ ve

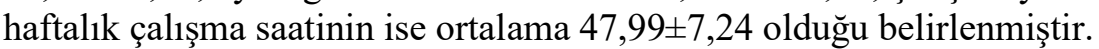

Tablo 2: Sağlık Çalışanlarına Ait Kişisel Verilerin Dağılımı (N=200)

\begin{tabular}{|c|c|c|c|}
\hline & & $\mathbf{N}$ & $\%$ \\
\hline \multirow[t]{2}{*}{ Cinsiyet } & Kadın & 132 & 66 \\
\hline & Erkek & 68 & 34 \\
\hline \multirow[t]{2}{*}{ Medeni Durum } & Evli & 123 & 61,5 \\
\hline & Bekar & 77 & 38,5 \\
\hline \multirow[t]{4}{*}{ Eğitim } & Lise & 61 & 30,5 \\
\hline & Önlisans & 31 & 15,5 \\
\hline & Lisans & 76 & 38 \\
\hline & Yüksek lisans/doktora & 32 & 16 \\
\hline \multirow{2}{*}{$\begin{array}{c}\text { Hafta Sonu } \\
\text { Çalışma Durumu }\end{array}$} & Evet & 174 & 87 \\
\hline & Hayır & 26 & 13 \\
\hline \multirow{2}{*}{$\begin{array}{c}\text { İdari Görevde } \\
\text { Bulunma } \\
\text { Durumu }\end{array}$} & Evet & 51 & 25,5 \\
\hline & Hayır & 149 & 74,5 \\
\hline \multirow[t]{5}{*}{ Çalışma Statüsü } & Hemşire & 125 & 62,5 \\
\hline & Doktor & 32 & 16 \\
\hline & FTR & 11 & 5,5 \\
\hline & Laboratuvar & 20 & 10 \\
\hline & Diğer & 12 & 6 \\
\hline \multirow[t]{2}{*}{ Dernek Üyeliği } & Var & 38 & 19 \\
\hline & Yok & 162 & 81 \\
\hline Yaş (ortalama) & $31,36 \pm 11,38$ & Çalışma yılı & $10,06 \pm 10,29$ \\
\hline Aylık gelir (TL) & $4096,10 \pm 3851,62$ & Haftalık çalışma saati & $47,99 \pm 7,24$ \\
\hline
\end{tabular}

\subsection{Genel Politik Etkinlik Ölçeği’ne Ait Bulgular}

Politik etkinlik kavramı ile ilgili alan yazın taraması yapılmıştır. Ulusal ve uluslararası politik etkinlik kavramına yönelik kalitatif çalışmalar, benzer alanda oluşturulmuş ölçekler ile psikometrik test ifadeleri, temel politika kitapları, araştırmacıların bilgi ve deneyimleri 
doğrultusunda 56 maddelik havuz hazırlanmıştır. İlgili ölçeğin geliştirilmesi sürecinde yüzey geçerliliği, kapsam geçerliliği, yapı geçerliliğini belirlemek için ise açıklayıcı ve doğrulayıcı faktör analizi yöntemleri uygulanmıştır. Ölçeğin güvenirlik analizinde Cronbach Alpha, Spearman-Brown ve Guttman katsayıları incelenmiştir. Zaman göre değişmezlik analizi ile ölçek geliştirme süreci tamamlanmıştır.

\subsubsection{Geçerlilik Analizleri}

Politik Etkinlik Ölçeği’ni geliştirmek amacıyla istatiksel aşamalarda ilk olarak geçerlilik analizleri yapılmıştır. Araştırmanın geçerlik analizinde; yüzey, kapsam ve yapı geçerliliği sınanmıştır.

\subsubsection{Yüzey Geçerliliği}

Araştırmacıların ve yakın çevresindeki meslektaşlarının görüşleri ile ayrıntılı değerlendirmeler alınmıştır. Geri bildirimler sonucunda herhangi bir sorunla karşılaşılmamıştır. Ölçeğin yüzey geçerliliği sağlanmıştır.

\subsubsection{Kapsam Geçerliliği}

Alanında uzman ve yeterliliği olan 10 uzmana görüşleri için 'Uzman Değerlendirme Formu” e-mail yoluyla ulaştırılmıştır. Görüşlerini her bir madde için "uygun”, "uygun, ancak ufak değişiklikler gerekiyor" ve "uygun değil" olarak değerlendirmişlerdir. Kapsam geçerlik oranları (KGO) Lawshe tekniği ile hesaplanmıştır. Değerlendirmede Veneziano ve Hooper tarafindan belirlenen minumum KGO ölçütleri kullanılmıştır (Veneziano ve Hooper, 1997). KGO değeri 10 uzman için 0,62 'dir. Bu durumda KGO değeri negatif “ 0 ” ve 0,62 'dan düşük olan 26 madde çıkartılmıştır. Kalan 30 maddelik taslak ölçeğin Kapsam Geçerlilik İndeksi (KGI), taslak ölçek alt gruplara ayrılmadığından tümü için, 0,80 olarak bulunmuştur. $\mathrm{Bu}$ durumda KGİ $>$ KGO $(0,80>0,62)$ olduğundan oluşturulan tüm ölçeğin kapsam geçerliliği istatistiksel olarak anlamlıdır $(\mathrm{p}<0,05)$.

\subsubsection{Yapı Geçerliliği}

İstatiksel aşamalarda bu kısımda geliştirilmek istenilen ölçeğin açıklayıcı ve doğrulayıcı faktör analizleri yapılmıştır. Elde edilen bulgular istatiksel açıdan sunulmuştur.

\subsubsection{Açıklayıcı Faktör Analizi}

Örneklem büyüklüğ̈̈nün faktör analizi yapmak için uygunluğunun saptanmasında KaiserMeyer-Olkin (KMO) ve Barlett Sphericity testleri yapılmıştır. Ölçeğin KMO örneklem uygunluk katsay1s1 0,898 ve Barlett Sphericity Testi $\chi^{2} / \mathrm{df}$ değeri 5697,774/325 (p=0,000) olarak saptanmıştır. Veriler, faktör analizi için uygun büyüklüktedir.

Yapılan açıklayıcı faktör analizinde alt kesme noktası olarak 0,40 olarak kabul edilmiş (Coombs ve Schroeder, 1988) ve 4 (dört) maddenin faktör yük değerinin 0,40'1n altında kaldığı belirlenmiştir. Taslak ölçek maddelerinin faktör yükleri Tablo 3 'te sunulmuştur. 
Tablo 3: Taslak Genel Politik Etkinlik Ölçeği’nin Faktör Yükleri (N=200)

\begin{tabular}{|c|c|c|}
\hline Madde No & Faktör 1 & Faktör 2 \\
\hline "Politik bilgim yeterli düzeydedir." & * &, 519 \\
\hline "Politik süreçler bana çok zor gelir." & $*$ & $*$ \\
\hline "Politikaya katılmaya gayret gösteririm." & $*$ & ,653 \\
\hline "Politikadan çekinirim." & * & $*$ \\
\hline “Önerilerim mutlaka kararlara yansitılır." &, 765 & $*$ \\
\hline "Politikaları sadece uygularım." & $*$ & $*$ \\
\hline "Politikada mutlaka yer almak isterim." & $*$ & ,681 \\
\hline "Karar vericiler mutlaka iş birliği yapar." &, 821 & $*$ \\
\hline "Politik süreçlerde dikkatli ve özenli davranırım." & * &, 571 \\
\hline "Sorunları tartışmak üzere firsat tanınır." &, 849 & $*$ \\
\hline "Politikada kendime güvenirim." & $*$ & 699 \\
\hline "Müzakere ortamı vardır." &, 801 & $*$ \\
\hline "Politikaya katılmamda herhangi bir engelim yoktur." & * &, 554 \\
\hline "Politika oluşturma sürecinde bilgi verilir." & ,614 & $*$ \\
\hline "Politik süreçlerde fikir birliği önemsenir." &, 599 & $*$ \\
\hline "Politik konularda kararlı davranırım." & $*$ &, 550 \\
\hline "Karar vericiler, politikaya katılımı teşvik eder." & ,705 & $*$ \\
\hline "Geri bildirimlerim dikkate alınır." &, 833 & $*$ \\
\hline "Politik konularda rahatlıkla fikir belirtebilirim." & * &, 564 \\
\hline "Karar vericiler ihtiyaçlarımı değerlendirir" &, 546 & $*$ \\
\hline "Politikaları çok yönlü değerlendirebilirim" & & ,616 \\
\hline "Politik görüşlerim dikkate alınır." &, 832 & $*$ \\
\hline "Eğitim düzeyim politik süreçler için yeterlidir." & $*$ &, 569 \\
\hline "Karar vericilerle iletişim kolaydır." & 672 & \\
\hline "Politik süreçleri etkileyebilirim." & $*$ & ,767 \\
\hline "Politik hedeflerim vardır." & $*$ & $*$ \\
\hline "Politik süreçlerde sonuç alıncaya kadar uğraşırım." & $*$ & ,709 \\
\hline "Politik kararlara ilişkin kararlarım desteklenir." &, 787 & \\
\hline "Politika ile ilgili fikir üretebilirim." & $*$ & ,713 \\
\hline "Politikada kendimi değerli hissederim." & ,862 & \\
\hline
\end{tabular}


Faktör yükü 0,40 üzeri olan maddeleri boyutlandırmada öz değer katsayısı dikkate alınır. Faktör belirlemede 2 adet kırılma noktası bulunmuştur. Şekil 1'de faktör öz değerlerine ait yığın grafiği görülmektedir.

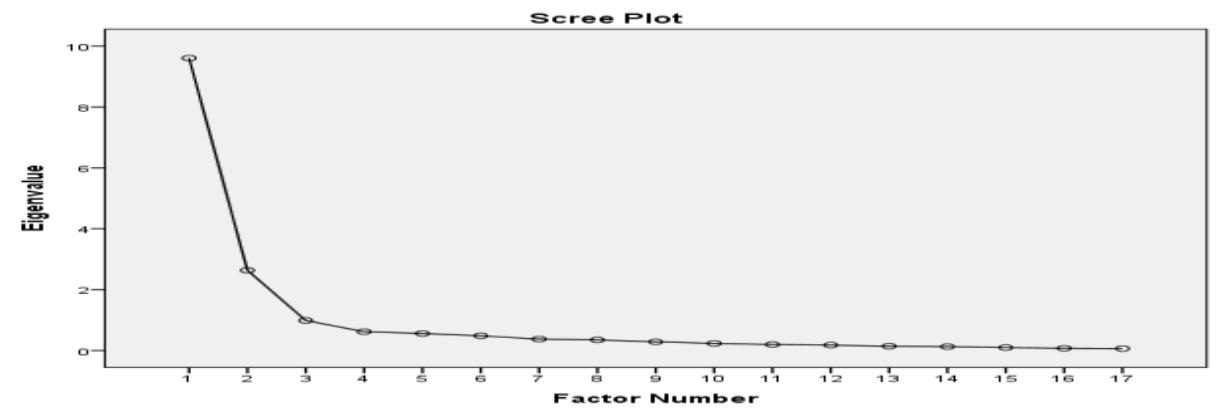

Şekil 1: Genel Politik Etkinlik Ölçeğinin Alt Boyutlarına Ait Yığın Grafiği

Taslak ölçeğin açıklanan toplam varyans miktarı \%65,41 olarak belirlenmiştir. Ölçeğin faktör analizi neticesinde ortaya çıkan alt boyutların özdeğeri ve açıkladığı varyans miktarı Tablo 4'te verilmiştir.

Tablo 4: Ölçeğin Alt Boyutları Tarafından Açıklanan Varyans Oranı (N=200)

\begin{tabular}{cccc}
\hline \multirow{2}{*}{ Faktör } & \multicolumn{3}{c}{ Başlangıç Özdeğerleri } \\
\cline { 2 - 4 } & Toplam & Varyans \% & Kümülatif \% \\
\hline 1 & 13,351 & 51,351 & 51,351 \\
\hline 2 & 3,658 & 14,068 & 65,419 \\
\hline
\end{tabular}

Açıklayıcı faktör analizi sonucunda 2 boyuttan ve 26 maddeden oluşan Genel Politik Etkinlik Ölçeği ortaya çıkmıştır. Boyutlara verilen isimler ve boyutları oluşturan madde numaraları Tablo 5'te gösterilmiştir. Faktör döndürmede Varimax Döndürme (Rotation) metodu kullanılmıştır. Faktör döndürme sonrasında ölçeğin iki alt boyut altında toplandığı görülmüştür. Birinci alt boyuta İçsel alt boyutu ismi verilmesinin nedeni; sağlık çalışanlarının kendi etkinlikleri ve buna olan inançlarını kapsamasından dolayıdır. İkinci alt boyuta dışsal isminin verilmesinin nedeni ise, dışarıda gelişen politik süreçlere yönelik hisleri "dışsal" politik etkinlik düzeyini belirlemeye yönelik olmasından dolayıdır. Ölçeğin birinci (İÇSEL) alt boyutunun 13 maddeden $(1,3,7,9,11,13,16,19,21,23,25,27,29)$, ikinci (DIŞSAL) alt boyutunun 13 maddeden $(5,8,10,12,14,15,17,18,20,22,24,28,30)$ oluştuğu belirlenmiştir.

Tablo 5: Ölçeğin Alt Boyut İsimleri ve Madde Numaraları ( $\mathrm{N}=200)$

\begin{tabular}{|c|c|}
\hline Boyut İsimleri & Madde No \\
\hline 1. Boyut: İçsel & $1,3,7,9,11,13,16,19,21,23,25,27,29$ \\
\hline 2. Boyut: Dışsal & $5,8,10,12,14,15,17,18,20,22,24,28,30$ \\
\hline
\end{tabular}


Tablo 5'te ölçek maddelerinin içerikleri doğrultusunda boyutlar isimlendirilmiştir. İlk boyutta sağlık çalışanlarının kendi etkinlikleri ve buna olan inançları "içsel", ikinci boyutta kendisi dışlarında gelişen politik süreçlere yönelik hisleri "dışsal" politik etkinlik düzeyini ölçmüştür. Adlandırmada politik etkinlin, yetkinlik ile ilişkili kavramlardan yararlanılmıştır.

\subsubsection{Doğrulayıcı Faktör Analizi (DFA)}

Açıklayıcı faktör analizinde ortaya çıkan iki faktörlü yapının yapı geçerliliği testinin ikinci adımı olan doğrulayıcı faktör analizi yapılmıştır. Her bir indeksin uygunluk değeri için Çokluk ve arkadaşlarının önerdiği kabul edilebilir kesim değerleri dikkate alınmıştır (Çokluk vd., 2014). Belirtilen bu değerler, Tablo 6'da sunulmuştur.

Tablo 6: Uyum İndeksleri Kriter Değerleri ve Ölçeğe İlişkin Uyum İndeksi Değerleri $(\mathrm{N}=\mathbf{2 0 0})$

\begin{tabular}{cccc}
\hline Uyum İndeksleri & İyi uyum & Kabul Edilebilir Uyum & $\begin{array}{c}\text { Ölçekten elde } \\
\text { edilen değerler }\end{array}$ \\
\hline$\chi^{2} / \mathrm{sd}$ & $0 \leq \chi^{2} / \mathrm{sd} \leq 2$ & $2<\chi^{2} / \mathrm{sd} \leq 5$ & 2,07 \\
\hline RMSEA & $0 \leq \mathrm{RMSEA} \leq .05$ &, $05<\mathrm{RMSEA} \leq, 08$ & 0,04 \\
\hline RMR & $0 \leq \mathrm{RMR} \leq .05$ &, $05<\mathrm{RMR} \leq, 08$ & 0,06 \\
\hline IFI & $, 95 \leq \mathrm{IFI}<1,00$ &, $90 \leq \mathrm{IFI}<, 95$ & 0,93 \\
\hline CFI & $, 95 \leq \mathrm{CFI}<1,00$ &, $90 \leq \mathrm{CFI}<, 95$ & 0,92 \\
\hline GFI & $, 95 \leq \mathrm{GFI}<1,00$ &, $80 \leq \mathrm{GFI}<, 95$ & 0,93 \\
\hline AGFI & $, 95 \leq \mathrm{GFI}<1,00$ &, $80 \leq \mathrm{GFI}<, 95$ & 0,90 \\
\hline
\end{tabular}

Tablo 6'da DFA analizinde; elde edilen indeks kriterlerinin yeterli düzeyde olduğu görülmektedir. İçsel ve Dışsal etkinlik alt boyutlarının DFA diyagramı Şekil 2'de gösterilmiştir. 


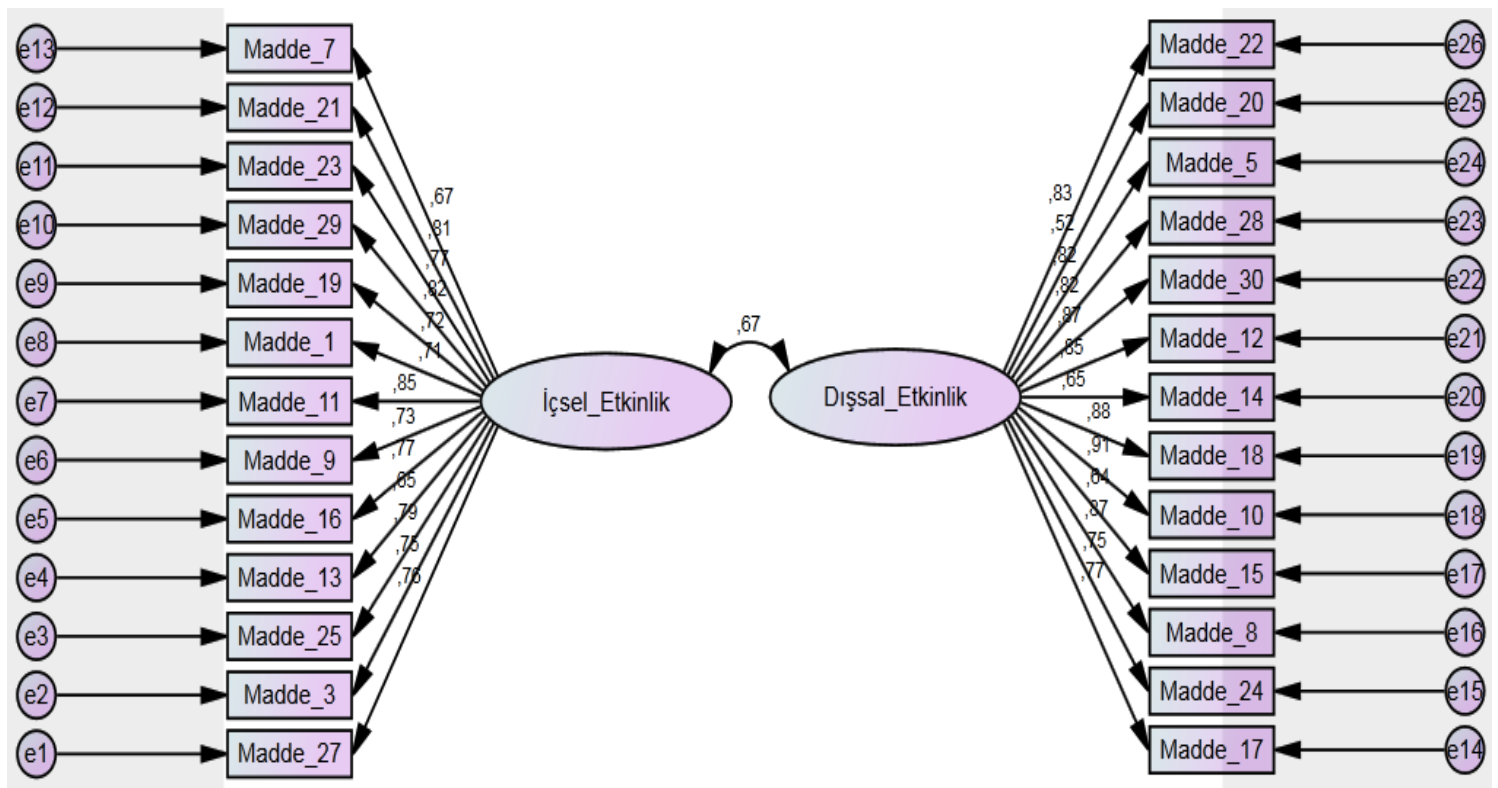

Şekil 2: Genel Politik Etkinlik Ölçeği DFA Şeması

\subsubsection{Güvenirlik Analizleri}

Araştırmada güvenirlik analizinde; madde analizleri, Cronbach Alpha katsayısı, Spearman-Brown, Guttman iç tutarlılık katsayıları ve test-tekrar test korelasyonları kullanılmıştır.

\subsubsection{Madde analizi}

Genel Politik Etkinlik Ölçeği'nin güvenirlik analizi için 26 ifadenin madde toplam puan korelasyon katsayı değeri 0,542 ile 0,824 arasında değiştiği, maddelerin pozitif yönlü ve istatistiksel açıdan ileri düzeyde anlamlı ilişki gösterdiği belirlenmiştir $(\mathrm{p}<0,001)$.

\subsubsection{2. İç Tutarlıık Katsayıları}

Genel Politik Etkinlik Ölçeği'nin iç tutarlılık katsayı değerleri Cronbach Alpha 0,96'dır. Spearman-Brown 0,953, Guttman 0,941 olarak bulunmuştur (Tablo 7).

Tablo 7: Genel Politik Etkinlik Ölçeği Madde Toplam Korelasyon Analizi Sonuçları $(\mathrm{N}=\mathbf{2 0 0})$

\begin{tabular}{lcc}
\hline \multicolumn{1}{c}{ Madde No } & $\begin{array}{c}\text { Madde Toplam } \\
\text { Korelasyonu }\end{array}$ & $\begin{array}{c}\text { Madde Çıkarıldı̆̆ında } \\
\text { Cronbach Alpha } \\
\text { Düzeyi }\end{array}$ \\
\hline "Politik bilgim yeterli düzeydedir.” &, 542 &, 959 \\
"Politikaya katılmaya gayret gösteririm." &, 681 &, 958 \\
"Politik konularda kararlı davranırım." &, 640 &, 959 \\
"Politikada mutlaka yer almak isterim." &, 697 &, 958
\end{tabular}


"Politikada kendime güvenirim."

"Politik süreçlerde sonuç alıncaya kadar uğraşırım."

"Eğitim düzeyim politik süreçler için yeterlidir."

"Politikaya katılmamda herhangi bir engelim yoktur."

"Politik süreçlerde dikkatli ve özenli davranırım."

"Politik konularda rahatlıkla fikir belirtebilirim."

"Politikaları çok yönlü değerlendirebilirim."

"Politik süreçleri etkileyebilirim."

"Politika ile ilgili fikir üretebilirim."

"Karar vericiler ihtiyaçlarımı değerlendirir."

“Politik görüşlerim dikkate alınır."

“Önerilerim mutlaka kararlara yansıtılır."

"Karar vericiler mutlaka iş birliği yapar."

"Politika oluşturma sürecinde bilgi verilir."

"Politik süreçlerde fikir birliği önemsenir."

"Karar vericiler, politikaya katılımı teşvik eder."

Ölçeğin alt boyutlarına ilişkin madde analizi ve iç tutarlık katsayıları Tablo 8'de gösterilmiştir. İçsel alt boyutu için Cronbach Alpha değeri 0,939 olarak bulunurken dişsal alt boyutu için ise Cronbach Alpha değeri 0,949 olarak bulunmuştur. 
Tablo 8: Ölçeğin Alt Boyutlarına İlişkin Madde Analizi Sonuçları ve İç Tutarlılık Katsayıları ( $\mathbf{N}=\mathbf{2 0 0})$

\begin{tabular}{|c|c|c|c|}
\hline & $\begin{array}{c}\text { Madde toplam puan } \\
\text { Korelasyonu* }\end{array}$ & $\begin{array}{l}\text { Madde çıkarıldığında } \\
\text { Cronbach Alpha düzeyi }\end{array}$ & \\
\hline \multicolumn{4}{|l|}{ İçsel Alt Boyutu } \\
\hline $\begin{array}{l}\text { "Politikada mutlaka yer } \\
\text { almak isterim." }\end{array}$ & ,606 & ,938 & \\
\hline $\begin{array}{l}\text { "Politikaları çok yönlü } \\
\text { değerlendirebilirim." }\end{array}$ &, 783 & ,932 & \\
\hline $\begin{array}{l}\text { "Eğitim düzeyim politik } \\
\text { süreçler için yeterlidir." }\end{array}$ & ,733 & ,934 & \\
\hline $\begin{array}{l}\text { "Politika ile ilgili fikir } \\
\text { üretebilirim." }\end{array}$ & ,789 & ,932 & \\
\hline $\begin{array}{lr}\text { "Politik } & \text { konularda } \\
\text { rahatlikla } & \text { fikir } \\
\text { belirtebilirim." } & \end{array}$ & 682 & ,935 & \\
\hline $\begin{array}{l}\text { "Politik bilgim yeterli } \\
\text { düzeydedir." }\end{array}$ & 677 & ,936 & Cronbach Alpha 0,939 \\
\hline $\begin{array}{l}\text { "Politikada } \\
\text { güvenirim." }\end{array}$ &, 816 & ,931 & $\begin{array}{l}\text { Spearman-Brown* } \\
0,958 \\
\text { Guttman* } 0,0,948\end{array}$ \\
\hline $\begin{array}{l}\text { "Politik süreçlerde dikkatli } \\
\text { ve özenli davranırım." }\end{array}$ & ,701 & ,935 & \\
\hline $\begin{array}{l}\text { "Politik konularda kararlı } \\
\text { davranırım." }\end{array}$ &, 724 & ,934 & \\
\hline $\begin{array}{l}\text { "Politikaya katılmamda } \\
\text { herhangi bir engelim } \\
\text { yoktur." }\end{array}$ & ,608 & ,938 & \\
\hline $\begin{array}{l}\text { "Politik süreçleri } \\
\text { etkileyebilirim." }\end{array}$ &, 732 & ,934 & \\
\hline $\begin{array}{l}\text { "Politikaya katılmaya } \\
\text { gayret gösteririm." }\end{array}$ & ,707 & ,935 & \\
\hline $\begin{array}{l}\text { "Politik süreçlerde sonuç } \\
\text { alıncaya kadar uğraşırım." }\end{array}$ & ,707 & ,935 & \\
\hline \multicolumn{4}{|l|}{ Dışsal Alt Boyutu } \\
\hline $\begin{array}{l}\text { "Karar vericiler, politikaya } \\
\text { katılımı teşvik eder." }\end{array}$ & ,808 & ,943 & $\begin{array}{c}\text { Cronbach Alpha 0,949 } \\
\text { Spearman-Brown* } \\
0,945\end{array}$ \\
\hline $\begin{array}{l}\text { "Karar vericilerle iletişim } \\
\text { kolaydır." }\end{array}$ &, 768 & ,944 & Guttman* 0,951 \\
\hline
\end{tabular}




\begin{tabular}{|c|c|c|}
\hline $\begin{array}{l}\text { "Karar vericiler mutlaka iş } \\
\text { birliği yapar." }\end{array}$ &, 868 & ,940 \\
\hline $\begin{array}{l}\text { "Politik süreçlerde fikir } \\
\text { birliği önemsenir." }\end{array}$ &, 727 & ,946 \\
\hline $\begin{array}{l}\text { "Sorunları tartışmak üzere } \\
\text { fırsat tanınır." }\end{array}$ &, 841 & ,941 \\
\hline $\begin{array}{l}\text { "Geri bildirimlerim } \\
\text { dikkate alınır." }\end{array}$ & ,839 & ,942 \\
\hline $\begin{array}{l}\text { "Politika oluşturma } \\
\text { sürecinde bilgi verilir." }\end{array}$ &, 725 & ,946 \\
\hline "Müzakere ortamı vardır." & ,797 & ,943 \\
\hline $\begin{array}{l}\text { "Politikada kendimi } \\
\text { değerli hissederim." }\end{array}$ &, 809 & ,943 \\
\hline $\begin{array}{l}\text { "Politik kararlara ilişkin } \\
\text { kararlarım desteklenir." }\end{array}$ &, 737 & ,945 \\
\hline $\begin{array}{l}\text { "Önerilerim mutlaka } \\
\text { kararlara yansitılır." }\end{array}$ & ,709 & ,946 \\
\hline $\begin{array}{lr}\text { "Karar } & \text { vericiler } \\
\text { ihtiyaçlarımı değerlendirir" }\end{array}$ &, 568 & ,951 \\
\hline
\end{tabular}

Belirlenen boyutlarda yer alan maddelerin tamamı istatistiksel açıdan anlamlıdır $(\mathrm{p}<0,01)$. Faktör analizine göre belirlenen maddelerin belirlenen boyutlar altında kalmalarına karar verilmiştir.

\subsubsection{Zamana Göre Değişmezlik Analizi (Test-Tekrar Test Uygulaması)}

Taslak ölçek test-tekrar test güvenirliği için örneklem grubuna benzeyen seçilmiş 30 sağlık çalışanına uygulanmıştır. Test tekrar test uygulaması için 30 kişinin olması yeterli olarak görülmüştür Şahin ve Dişsiz (2009). İlk uygulama yapıldıktan sonra iki hafta sonrasında aynı kişilere gidilerek ölçek formunu tekrar doldurmaları istenmiştir. Ölçeğin Test-Tekrar Test analizi değerleri Tablo 9'da gösterilmiştir.

Tablo 9: Ölçeğin Test-Tekrar Test Güvenirlik Katsayısı (N=30)

\begin{tabular}{lcc}
\hline & r (korelasyon katsayısı) & $\begin{array}{c}\text { P (olasilık; p- } \\
\text { değeri) }\end{array}$ \\
\hline Genel Politik Etkinlik Ölç̧ği & 0,953 & 0,000 \\
İçsel alt boyutu & 0,914 & 0,000 \\
Dışsal alt boyutu & 0,922 & 0,000 \\
\hline
\end{tabular}


İki ölçüm arasında istatiksel açıdan ileri düzeyde anlamlı ve pozitif yönlü bir ilişkinin olduğu görülmüştür $(\mathrm{p}<0,001)$.

Sonuç olarak; iki alt boyutlu ve maddeli olarak son hali verilen ölçekte; içsel politik etkinlik düzeyini; $1,3,7,9,11,13,16,19,21,23,25,27,29$ maddeler, dişsal düzeyini; 5, 8, 10, $12,14,15,17,18,20,22,24,28,30$. maddeler ölçmektedir. Tüm maddeler düz puanlanmaktadır. Ölçekten alınan puan 26-130 arasındadır. Alınan puan arttıkça politik etkinlik düzeyi de artacaktır.

Alt boyut puan aralıkları; içsel alt boyut için 13-65, dişsal alt boyut için 13-65'dir. Puanlar arttıkça politikayla içsel ve dışsal etkinlik düzeyleri artacaktır. Alan yazınına yeni kazandırılan Genel Politik Etkinlik Ölçeği istatistiksel olarak geçerli ve güvenilir bir araçtır.

\section{TARTIŞMA}

$\mathrm{Bu}$ araştırmada, sağlık çalışanlarının politik etkinlik düzeylerini belirlemek amacı ile Genel Politik Etkinlik Ölçeği geliştirilmiştir. Sağlık çalışanlarının politik etkinliklerini ölçen herhangi bir çalışma bulunamaması nedeniyle bu ölçüm aracının geliştirilmesine karar verilmiştir. Yeni geliştirilen bir testin de geçerli ve güvenilir olması gerekir.

Geçerlik: Bir ölçeğin ölçmek istediği değişkeni ölçüp ölçmediği, eğer ölçüyorsa onu başka değişkenlerden ne derece ayırarak ölçtüğünü belirtmektedir (Borsboom vd., 2004). Bu çalışmada, ilgili ölçeğin geçerliliğini ortaya koymak amacıyla yüzey, kapsam ve yapı geçerliliği analizlerinden yararlanılmıştır.

Yüzey Geçerliliği: Taslak ölçeğin araştırılmak istenilen yapıyı ölçüp ölçmediğine yönelik olarak araştırmacının kendisi, yakın çevresindeki arkadaşları, araştırılan konu hakkında uzman olmayan ve pilot çalışmaya katılan diğer kişilerin görüşlerinden yararlanılmasıdır (Öztürk ve Babacan, 2012). Bu çalışmada araştırmacıların görüşlerinden yararlanılmış havuz maddelerinin her birinin uygunluğu test edilmiştir. Ölçeğin yüzey geçerliliği sağlanmıştır.

Kapsam Geçerliliği: Ölçekte her bir maddenin amaca ne derece hizmet ettiği ortaya konulmaktadır. Bu sayede geliştirilen ölçekte çalışılan konu harici ilgisiz ifadeler yerine konuyu temsil gücü yüksek ifadelere yer verilir (Wilson vd., 2012; Ayre ve Scally, 2014). Taslak ölçek, kapsam geçerliliğini sınamak amaciyla uzmanların görüşüne sunulmuştur. Görüşüne başvurulacak uzman sayısı 5 ile 40 arasında olmalıdır. Bu çalışmada, hazırlanan maddeler 10 uzman ile değerlendirilmiştir. Kapsam Geçerlilik Oranı hesaplanmasında Lawshe tekniği kullanılmıştır (Lawshe, 1975; Ayre ve Scally, 2014). KGO, 10 uzman için 0,62'dir. Bu durumda KGO'nı negatif, “0”, 0,62'dan düşük olan 26 madde çıkarılmıştır. Kalan 30 maddelik taslak ölçeğin Kapsam Geçerlilik İndeksi (KGI), taslak ölçek alt gruplara ayrılmadığından tümü için, 0,80 olarak bulunmuştur. Bu durumda $\operatorname{KGI}>\operatorname{KGO}(0,80>0,62)$ olduğundan oluşturulan tüm ölçeğin kapsam geçerliliği istatistiksel olarak anlamlıdır $(\mathrm{p}<0,05)$.

Yapı Geçerliliği: Yapı geçerliliğine bakılmadan önce örneklem sayısının faktör ayrımına uygun olup olmadığı sınanmalıdır. Uygunluk sağlandıktan sonra Genel Politik Etkinlik Ölçeğini ölçtüğü faktörlerin sayısı belli olmadığından, belli bir ölçeği sınamak yerine, ölçme aracıyla ölçülen faktörlerin doğası hakkında bilgi edinmeye çalışıldığ1 için açıklayıcı faktör analizi yapılmıştır (Büyüköztürk, 2014). 200 örneklem ve 30 madde için yapılan açıklayıcı faktör analizinde (Laher, 2010; Uyumaz vd., 2016; Girgin, 2016) alt kesme noktas1 0,40 olarak kabul edilmiş ve dört maddenin faktör yük değerinin 0,40 'ın altında kaldığı görülmüsstür. Faktör yükü 0,40 üzeri olan maddeleri boyutlandırmada ise özdeğer katsayısı dikkate alınır. Özdeğeri 1'den büyük olan faktörler anlamlı kabul edilir (Grant ve Davis, 1997). 26 maddenin içsel ve dişsal olmak üzere iki faktör altında toplandığı görülmüsstür. Faktör analizi sonrasında toplam varyans 
oranı $\% 65,41$ 'dir. Alan yazınında açılanan toplam varyansın $\% 40$ ile $\% 60$ arasında olması yeterli olarak kabul edilmektedir (Çokluk vd., 2014). Açıklanan varyansın literatüre uygun olduğu ifade edilebilir. Bu durumun önemine dikkat çeken Büyüköztürk açıklanan varyans değeri ne kadar yüksek olursa, ilgili kavram ya da yapının ne denli iyi ölçüldüğünün göstergesi olarak belirmektedir (Büyüköztürk, 2014).

Açıklayıcı faktör analizinden sonra doğrulayıcı faktör analizi yapılmıştır. Bir ölçeğin faktör yapısının kuramsal bilgilere uygun olması geçerlik ve güvenirlik çalışmalarında istenen bir unsurdur. Bu aynı zamanda test veya ölçeği güvenle kullanılabilecek hale getirme işlemidir (Alpar, 2012). Geliştirilen modelin uyum iyiliği indeksleri vasıtasıyla incelenmesi gerekir (Albright ve Park, 2009). DFA analizinde sınanan modelin tek bir testin sonucuna göre değil, çeşitli uyum indekslerinin sonucuna göre test işlemi uygulanır (Meydan ve Şeşen, 2015). DFA analizinde; $\chi^{2} / \mathrm{sd}: 2,07 ; \quad$ RMSEA:0,04; RMR:0,06; IFI:0,93; CFI:0,92; GFI:0,93 ve AGFI:0,90'dır. DFA analizinde uyum iyiliği indeks değerlerine bakıldığında sınanan modelin kullanılabilir olduğu görülmektedir.

Güvenirlik: Güvenirlilik katsayısı, ölçek maddelerinin homojenliğinin ve iç tutarlılığının bir ölçüsüdür (Tezbaşaran, 2008). Güvenirlilik katsayısının düşük olması, ölçeğin her ölçümde benzer sonuçlar üretmeyen, güvenilir olmayan bir ölçme aracı özelliği taşımasına neden olabilir (Tavşancıl, 2010). Ölçek güvenirliğini değerlendirmek için bu çalışmada; madde analizleri, Cronbach Alpha katsayısı, Spearman-Brown, Guttman iç tutarlılık katsayıları ve test-tekrar test korelasyonları kullanılmıştır.

Madde Analizi: İlgili ölçek maddelerinin ölçme aracının tamamıyla ne düzeyde ilişkili olduğunu belirlemektedir. Madde analizinin uygulanması için korelasyon katsayı değeri hesaplanır. Madde toplam korelasyonu test maddelerinden alınan puanlar ile testin toplam puanı arasındaki ilişkiyi açıklar ve ölçme aracındaki her bir maddenin benzer davranışları örneklediğini gösterir (Büyüköztürk, 2014). Bu doğrultuda, madde toplam korelasyonun pozitif ve yüksek olması gerekir (Alpar, 2012). İlgili ölçekte bir madde için korelasyon katsayısının yüksek olması o maddenin ölçtüğü kuramsal yapıyla bağlantısının yüksek olduğu ve maddenin hedeflenen davranışı ölçmek için yeterli ve etkin olduğunu gösterir (Büyüköztürk, 2014). Madde toplam puan korelasyon katsayısının 0,30'un üzerinde olması gerektiği önerilir (Tavşancı1, 2010). Genel Politik Etkinlik Ölçeğinin güvenirlik çalışması için 26 maddeden elde edilen madde toplam korelasyonları değerlendirildiğinde ilgili 26 maddenin korelasyon katsay değerlerinin, $r=0,542$ ile 0,824 arasında değiştiği, maddelerin pozitif yönlü ve istatistiksel açıdan ileri düzeyde anlamlı ilişki gösterdiği belirlenmiştir. Madde analizi çalışmaları sonucunda taslak ölçekten hiçbir madde çıkartılmamıştır.

İç Tutarlılık: Bir ölçme aracının, belirlenen bir amaç doğrultusunda (bütünü oluşturmak) üzere deneysel olarak birbirinden bağımsız ünitelerden (örneğin, anket sorularından, test maddelerinden) oluştuğu ve bunların tamamı içerisinde, bilinen ve birbirlerine eşit ağırlıklara sahip olduğu varsayımıdır (Karakoç ve Dönmez, 2014). Bunu ölçmede kullanılan, Cronbach's Alpha katsayısı 0-1 arasında değer almaktadır. Alan yazınında Cronbach's Alpha değerinin $0,60<0,80$ arasında değer alıyorsa ölçek oldukça güvenilir ve $0,80<1,00$ arasında değer alıyor ise ilgili ölçeğin yüksek derecede güvenilir olduğu ifade edilir (Tavşanc1l, 2010; Alpar, 2012). Genel Politik Etkinlik Ölçeği'nin Cronbach Alpha iç tutarlılık katsayısı 0,96'dır. Bu değer ölçeğin yüksek güvenilirliğe sahip olduğunun kanıtıdır.

Spearman-Brown, geliştirilen ölçeğin alt boyutları varsa her boyutun kendi içinde bütün kabul edilerek uygulanması ile elde edilen değerdir. Ölçeğin tamamının güvenirlik katsayısı için Spearman-Brown formülü uygulanır. Genel Politik Etkinlik Ölçeği’nin Spearman-Brown iç tutarlılık katsayısı 0,953 olarak hesaplanmıştır.

Genel Politik Etkinlik Ölçeği’nin Guttman iç tutarlılık katsayısı 0,941 olarak bulunmuştur. 
Zamana Göre Değişmezlik Analizi (Test-Tekrar Test Uygulaması): Zamana göre değişmezlik ölçütünü belirlemek için uygulanan analiz yöntemi ilgili ölçeğin belirli bir aralıkla aynı gruba, aynı koşullarda uygulanarak ve iki ölçüm arasındaki ilişkiye pearson momentler çarpımı korelasyon katsayısı ile incelenmesidir. Geliştirilen ölçeğin zamana karşı değişmez olduğunu ortaya koymak için hesaplanan korelasyon katsayı değerinin +1 'e yaklaştıkça aynı zamanda güvenirliği de artmaktadır. İki ölçüm arasındaki yapılan test tekrar korelasyon katsayı değerinin en az alan yazının da 0,70 olması istenmektedir (Tezbaşaran, 2008). Yapı geçerliliği, madde analizleri ve iç tutarlılığ 1 test edilen ölçek, test-tekrar test güvenirliği için örneklem grubuna benzeyen seçilmiş, 30 sağlık çalışanına uygulanmıştır. Test-tekrar test analizi için en az 30 kişinin alınması literatür tarafından önerilmektedir (Tavşancıl, 2010). İlk uygulama yapıldıktan iki hata sonrasında ikinci defa aynı kişilere gidilerek ölçek formlarını tekrar doldurmaları istenmiştir. Yapılan analiz neticesinde iki ölçüm arasında pozitif yönlü ve istatiksel açıdan ileri düzeyde anlamlı bir ilişkinin olduğu belirlenmiştir $(p<0,001)$. İki hafta süreyle yapılan test tekrar güvenirlik analizlinde iki uygulama arasındaki hesaplanan korelasyon katsayı değerinin oldukça yüksek olduğu görülmüştür. Buna göre ilgili ölçeğin kararlılıkla aynı yapıyı ölçtüğünü ortaya çıkarmaktadır.

\section{SONUÇ VE ÖNERILER}

Araştırmacılar tarafından yapılan araştırmalarda sağlık çalışanlarının politik etkinlik düzeylerinin belirlenmesine ilişkin herhangi bir ölçüm aracına rastlanmaması ve toplumsal alana pek çok etkisi olan politikadan faydalanabilmek amacıyla bu ölçeğin geliştirilmesine karar verilmiştir. Alan yazına yeni kazandırılan Genel Politik Etkinlik Ölçeği, istatistiksel olarak geçerli ve güvenilir bir araçtır.

Her araştırmada olduğu gibi bu çalışmanın da kısıtlılıkları bulunmaktadır. Araştırmanın Hatay ilinde bir özel hastaneden elde edilen veriler ile yapılmış olması araştırmanın kısıtlılıkları arasında yer almaktadır. Katılımcıların dürüst ve samimi bir şekilde anketleri cevaplamış olması varsayımı araştırmanın bir diğer önemli kısıtıdır. Çalışmada geliştirilen ölçeğin özel sağlık kurumundan elde edilen veriler ile ortaya konulmuş olması ölçeğin yalnızca özel sağlık kuruluşlarına yönelik olduğu şeklinde algılanmamalıdır. Sağlık sektöründe geliştirilen politikalar bir bütüncül niteliğe sahip olup kamu ve özel sağlık kurumlarının tamamını kapsamaktadır. Bu bağlamda Genel Politik Etkinlik Ölçeği farklı kurumları, farklı bölgeleri ve farklı meslek grupları ile uygulanabilir.

Geleceğe yönelik yapılması planlana araştırmalar arasında kamu ve özel sağlık kurumlarında çalışmaların yapılıp sağlı çalışanlarının politik etkinlik düzeylerinin karşılaştırılması ve sonuçların karşılaştııılması önerilmektedir. Çalışmanın literatürü ve bulguları ile diğer araştırmacılara ve uygulayıcılara katkı sağlayacağı düşünülmektedir. 


\section{KAYNAKÇA}

Albright, J.J. ve Park, H.M. (2009). Confirmatory factor analysis using Amos, LISREL, mplus, and SAS/STAT CALIS. Bloomington: University Information Technology Services Center for Statistical and Mathematical Computing Indiana University Press.

Almond, G.A. ve Verba, S. (1965). The civic culture: Political attitudes and democracy in five nations. Boston, MA, USA: Little, Brown and Co.

Alpar, R. (2012). Spor, sağllk ve eğitim bilimlerinden örneklerle uygulamalı istatistik ve geçerlik-güvenirlik, SPSS'de çözümleme adımlarıyla birlikte. Ankara: Detay Yayıncılık.

Ayre, C. ve Scally, A.J. (2014). Critical values for lawshe's content validity ratio: Revisiting the original methods of calculation. Measurement and Evaluation in Counseling and Development 47(1), 79-86.

Balch, G.I. (1974). Multiple indicators in survey research: The concept sense of political efficacy. Political Methodology, 1(2), 1-43.

Bandura, A. (1977). Self-efficacy: Toward a unifying theory of behavioral change. Psychological Review, 84(2), 191215 .

Bandura, A. (1982). Self-efficacy mechanism in human agency. American Psychologist, 37,122-147.

Bandura, A. (1991). Social cognitive theory of self-regulation. Organizational Behavior and Human Decision Processes, 50, 248-287.

Bennett, S.E. (1997). Knowledge of politics and sense of subjective political competence: The ambiguous connection. American Politics Research 25, 230-240.

Bilge, H. (2003). İnsan kaynaklarının sürekli artan gücü. Sosyal Bilimler, 1(1), 7-17.

Borsboom, D., Mellenbergh. G.J., \& Heerden, J.V. (2004). The concept of validity. Psychological Review, 111(4), 1061-1.

Büyüköztürk, Ş. (2014). Veri analizi el kitabı. Ankara: Pegem Akademi.

Campbell, A., Gurin, G., \& Miller, W.E. (1954). The voter decides. Evanston, IL, USA: Row, Peterson and Company.

Chitty, K.K. (2001). Professional nursing- concpts \& challenges. (3 rd ed.). Philadelphia, WB: Saunders.

Condon, M. ve Holleque, M. (2013). Entering politics: General self-efficacy and voting behavior among young people. Political Psychology, 34(2), 167-181.

Converse, P.E. (1972). Change in the American electorate. In A. Campbell, \& PE. Converse (Eds.), The human meaning of social change. New York, NY: Russell Sage.

Coombs, W. ve Schroeder, H. (1988). An analysis of factor analytic data. Personality and Individual Differences, 9,79-85.

Cornfield, M. (2003). Adding in the net: Making citizenship count in the digital age. In D. Anderson and M. Cornnfield (Eds.), The Clvlc Web. Oxford, UK: Woman And Littlefield Publishers.

Craig, S.C., Niemi, R.G., \& Silver, G.E. (1990). Political efficacy and trust: A report on the NES pilot study items. Political Behavior, 12, 289-314.

Çokluk, Ö., Şekercioğlu, G., \& Büyüköztürk, Ş. (2014). Sosyal bilimler için çok değişkenli istatistik: SPSS ve lisrel uygulamaları. Ankara: Pegem Akademi Yayıncılık.

Gallego, A. ve Oberski, D. (2012). Personality and political participation: The mediation hypothesis. Political Behavior, 34(3), 425-451.

Gastil, J. ve Dillard, J.P. (1999). Increasing political sophistication through public deliberation. Political Communication, 16, 3-23.

Gil de Zúñiga, H. (2006). Reshaping the digital inequality in the european union: How psychological variables affect internet adoption rates, Webology 3, Article 32. [Available online at: http://www.webology.org/2006/v3n4/a32.html], Erişism tarihi: 15.10 .2019 .

Girgin, D. (2016). Çalgı eğitiminde algılanan aile desteği ölçeği geliştirme çalışması. Elementary Education Online, 15(3), 778-786. 
Gist, E.M. ve Mitchell, T. (1992). Self-efficacy: A theoretical analysis of its determinants and malleability. The Academy Of Management Review, 17(2), 183-211.

Grant, J.S. ve Davis, L.L. (1997). Selection and use of content experts for instrument development. Research in Nursing \& Health, 20, 269-274.

Harmancı Seren, A.K. (2014). Sağlık sistemi, sağlık politikaları ve hemşirelik mevzuatı. İçinde Ü. Baykal Tatar ve E. Ercan Türkmen (Eds), Hemşirelik Hizmetleri Yönetimi. İstanbul: Akademi.

Johann, D. (2012). Specific political knowledge and citizens' participation: Evidence from Germany. Acta Politica, $47(1), 42-66$.

Johnson, T.J. ve Kaye, B.K. (2003). A boost or a bust for democracy? How the web influenced political attitudes and behaviors in the 1996 and 2000 presidential elections. Harvard International Journal of Press/Politics, 8(3), 9-34.

Jung, N., Kim, Y., \& Zúñiga, H.G. (2011). The mediating role of knowledge and efficacy in the effects of communication on political participation. Mass Communication \& Society, 14(4), 407-430.

Karakoç, A. ve Dönmez, P. (2014). Ölçek geliştirme çalışmalarında temel ilkeler. Tip Ĕgitimi Dünyası, 13(40), 39-49.

Kenski, K. ve Stroud, N.J. (2006). Connections between internet use and political efficacy, knowledge and participation. Journal of Broadcasting \& Electronic Media, 50(2), 173-192.

Krampen, G. (2000). Transition of adolescent political action orientations to voting behavior in early adulthood in view of a social-cognitive action theory model of personality. Political Psychology, 21(2), 277-299.

Kuşcu Karatepe, H. (2019). Hemşirelerde politik duyarlılık ve örgütsel demokrasi algısı arasındaki ilişsinin belirlenmesi. Doktora Tezi, İstanbul Üniversitesi-Cerrahpaşa Lisansüstü Eğitim Enstitüsü.

Laher, S. (2010). Using exploratory factor analysis in personality research: Best-practice recommendations. $S A$ Journal of Industrial Psychology, 36(1), 1-7.

Lawshe, C.H. (1975). Aquantitative approach to content validity. Personnel psychology, 28(4), 563-575.

McLeod, J.M. ve McDonald, D.G. (1985). Beyond simple exposure: Media orientations and their impact on political processes. Communication Research, 12, 3-33.

Meydan, C.H. ve Şeşen, H. (2015). Yapısal eşitlik modellemesi amos uygulamaları. Ankara: Detay Yayıncılık.

Mill, J.S. (1991). Considerations on representative government. In J. Gray (Ed.), On liberty and other essays. Oxford, UK: Oxford University Press.

Mohammed, A.K.A. (2011). Students' exposure to political news on the internet and political awareness: A comparison between Germany and Egypt. Doktora Tezi, Dresden Teknik Üniversitesi İletişim Bilimleri Enstitüsü.

Morrell, M.E. (2003). Survey and experimental evidence for a reliable and valid measure of internal political efficacy. Public Opinion Quarterly, 67,589-602.

Niemi, R.G., Craig, S.C., \& Mattei, F. (1991). Measuring internal political efficacy in the 1988 national election study. The American Political Science Review, 85(4), 1407-1413.

Öztürk, H. ve Babacan, E. (2012). Bir ölçek geliştirme çalışması: Hastanede çalışan sağlık personeli için iş güvenliği ölçeği. Hemşirelikte Ĕ̆itim ve Araştırma Dergisi, 9(1), 36-42.

Pingree, J.R. (2011). Effects of unresolved factual disputes in the news on epistemic political efficacy. Journal of Communication, 61(1), $22-47$.

Schulz, W., Ainley, J., Fraillon, J., Kerr, D., \& Losito, B. (2010). ICCS 2009 International report: Civic knowledge, attitudes, and engagement among lower-secondary school students in 38 Countries. Amsterdam, The Netherlands: IEA.

Şahin, N. ve Dişsiz, M. (2009). Sağlık çalışanlarında aile içi şiddete yönelik tutum ölçeği geliştirme çalışması. Uluslararası Insani Bilimler Dergisi, 6(2), 263-274.

Tavşancıl, E. (2010). Tutumların ölçülmesi ve SPSS ile veri analizi. Ankara: Nobel Yayıncılık.

Tezbaşaran, A. (2008). Likert tipi ölçek geliştirme kılavuzu. Ankara: Türk Psikoloji Derneği Yayınları.

Uyumaz, G., Mor Dirlik, E., \& Çokluk, Ö. (2016). Açıklayıcı faktör analizinde tekrar edilebilirlik: Kavram ve uygulama. Abant İzzet Baysal Üniversitesi Ĕ̈itim Fakültesi Dergisi, 16(2), 659-675.

Velasquez, A. ve LaRose, R. (2015). Social media for social change: Social media political efficacy and activism in student activist groups. Journal of Broadcasting \& Electronic Media, 59, 456-474. 
Veneziano, L. ve Hooper, J. (1997). A method for quantifying content validity of health-related questionnaires. American Journal of Health Behavior, 21(1), 67-70.

Wang, S.I. (2007). Political use of the internet, political attitudes and political participation. Asian Journal of Communication, 17(4), 381-395.

Westle, B. (2011). Politisches wissen in deutschland: Ein vergleich von bürgern mit türkischem migrationshintergrund und einheimischen Deutschen. Zeitschrift für Parlamentsfragen, 42(4), 835-850.

Wilson, F.R., Pan, W., \& Schumsky, D.A. (2012). Recalculation of the critical values for lawshe's content validity ratio. Measurement and Evaluation in Counseling and Development, 45, 197-210.

Yıldırım, A. (2014). Onkoloji hemşireliği. İçinde Can, G. (Ed.), Onkoloji hemşireliğinde mesleki boyut, Türkiye'de hemşirelik haklar ve sorumluluklar. İstanbul: Nobel Tıp Kitabevleri.

Yurdugül, H. (2005). Ölçek geliştirme çalışmalarında kapsam geçerliği için kapsam geçerlik indekslerinin kullanılması. XIV. Ulusal Ĕgitim Bilimleri Kongresi. Bildiri Kitabı. Pamukkale Üniversitesi Eğitim Fakültesi, (28-30 Eylül 2005).

Zimmerman, B.J. (1989). A social cognitive view of self-regulated academic learning. Journal of Educational Psychology, 81, 329-339. 


\section{Extended Summary}

\section{General Political Activity Scale: A Scale Development Study In Healthcare Employees}

The research was carried out methodologically with the aim of developing a measurement tool in determining the political effectiveness levels of healthcare employees. April-December 2019 was conducted at a private hospital in Hatay province. The universe of the research is all health employees working in a private health organization in Hatay province. April-December 2019 at a private hospital in Hatay province and volunteered to participate in the study by means of random sampling method, the sample of the study consisted of 200 health employees. In scale studies of the research universe and sampling, it is suggested that a minimum of five times or more of each Scale item should be sampled. In this study, is the overall scale of political activity valid? Is the overall scale of political activity credible?

As data collection tools; the first form created by the researcher, health employees of the socio-demographic characteristics or personal information in order to determine the form and participant gender, marital status, education, working status weekend, the situation in administrative duties, the task of the association membership, monthly income, and weekly working hours a year of work to determine such properties as consist of 11 items. In the first phase of the scale, data were collected in draft form with a total of 30 items. The 26-point scale of political effectiveness, which is final with subsequent analyses, has emerged under two subdimensions, internal and external. In the course of the study, the methods of analysis applied are given in detail. In order to obtain the data, scale scoring of 5 Likert type was preferred. The scale scoring is" $1=$ disagree at all, $2=$ few agree, $3=$ agree, $4=$ quite agree, $5=$ totally agree". Scores between 1-2 were used to indicate the state of non-participation in the article in a decreasing way, and scores between 3-5 were used to indicate the state of participation in the article in an increasing way. All of the substances are positive expressions.

The ethical approval of this study (no.2019/4/3 dated 27/03/2019) was obtained from Osmaniye Korkut Ata University Scientific Research and publication ethics board; the application permit within the scope of the research was obtained from the Private Academy Hospital Chief Physician. In the distribution of personal data; $66 \%$ of respondents were female and $34 \%$ were male. As marital status; $61.5 \%$ were married and $38.5 \%$ were single. When education levels were examined, it was determined that $30.5 \%$ had a high school degree, $15.5 \%$ had an associate degree, $38 \%$ had a bachelor's degree and $16 \%$ had a master's degree/doctorate degree. As a weekend work situation, $87 \%$ of the participants were determined to work the weekend, while $13 \%$ were determined not to work the weekend. As a working status, $62.5 \%$ were nurses, $16 \%$ were doctors, $5.5 \%$ were physiotherapists, $10 \%$ were laboratory technicians and $6 \%$ were other unit employees of the health institution. $19 \%$ of the participants were found to have membership in the association, while $81 \%$ did not have membership in the Professional Association. The average age of the participants was $31.36 \pm 11.38$, the average monthly income was $4096.10 \pm 3851.62$, the average working year was $10.06 \pm 10$ and the weekly working hour was $47.99 \pm 7.24$.

The field paper on the concept of political activity has been scanned. Qualitative studies on the concept of national and international political effectiveness, psychometric test statements with similar scales, proposed basic policy books, 56-item pool was prepared in line with the knowledge and experiences of the researchers. In the development process of the related scale, explanatory and confirmatory factor analysis methods were preferred to determine surface validity, scope validity and structure validity. Cronbach Alpha, Spearman-Brown and Guttman coefficients were examined in the reliability analysis of the scale. The scale development process has been completed with time-relative invariance analysis. The validity of the surface and scope 
of the study was provided. After scope validity, the draft scale was determined to consist of 56 articles and 30 articles of draft scale. In the next phase, analyses were carried out on a 30-item draft scale. Kaiser-Meyer-Olkin (KMO) and Barlett Sphericity tests were performed to determine the suitability of the sample size for factor analysis. The KMO sample conformity coefficient of the scale was 0.898 and the Barlett Sphericity Test value of $\chi^{2 / D F}$ was $5697,774 / 325(\mathrm{p}=0.000)$.

The data is of appropriate size for factor analysis. In the explanatory factor analysis, the lower breakpoint was determined as 0.40 and was eliminated from the scale due to the fact that the factor load value of 4 (four) items remained below 0.40. The total amount of variance described in the draft scale is $65.41 \%$. After the Varimax rotation method, the draft scale was determined to consist of 2 dimensions and 26 items. Because of the names given to the dimensions and the contents of the substances that make up the dimensions, the first dimension is called the inner second dimension is called the extrinsic. In the explanatory factor analysis, the second step of the structure validity test of the two-factor structure was performed. Validating factor analysis of the two-dimensional draft scale has been observed to provide index criteria for the goodness of fit. As a result, the scale of political effectiveness is valid and credible. 
Optimum Journal of Economics and Management Sciences, Vo1. 7, No. 2- http://dergipark.org.trloptimum Kuşcu Karatepe and Atik - General Political Activity Scale: A Scale Development Study In Healthcare Employees 